\title{
Blood Pressure Control in an 11-Year Cohort of Diabetic and Non-Diabetic Individuals with Hypertension
}

Andréa C de Sousa*b ${ }^{\text {b }}$ Thiago 0 Costa ${ }^{\mathrm{b}}$, Fabrício Galdino Magalhães ${ }^{\mathrm{b}}$, Marcos PM Montelo ${ }^{\mathrm{a}}$, Weima KSB Souza ${ }^{b}$, Thiago SV Jardima, Paulo CBV Jardima ${ }^{\text {, Ana LL Sousa }}{ }^{a}$

${ }^{a}$ Hypertension League, Federal University of Goiás (Universidade Federal de Goiás), Brazil

${ }^{b}$ School of Medicine, Federal University of Goiás (Universidade Federal de Goiás), Brazil

Received: June 08, 2017; Accepted: June 28, 2017; Published: August 18, 2017

*Corresponding author: Andréa Cristina de Sousa, Nurse, Hypertension League of the Federal University of Goiás, 1ํㅡㄹ Avenida, S/N - Setor Leste Universitário, Goiania, Brazil, E-mail: andrea.c.sousa@hotmail.com

\begin{abstract}
Aim: To analyze Blood Pressure (BP) control among hypertensive individuals with or without type 2 Diabetes Mellitus (DM) who were followed over 11 years at a reference center.

Method: This was a historical cohort study of patients who were regularly treated for hypertension and who had DM as an exposure factor. Time-points of assessment: baseline - 2004, mid-term 2009 and final - 2015. Variables: gender, race, age, BP, Body Mass Index (BMI), and length of treatment at specialized service. The BP goals were $<140 / 90 \mathrm{mmHg}$ for non-diabetics with hypertension and $<130 / 80 \mathrm{mmHg}$ (stricter goal) or $<140 / 90 \mathrm{mmHg}$ (standard goal) for diabetics with hypertension. An association analysis was performed using the chi-square or Fisher's exact test, with a 5\% significance level.

Results: The sample included 139 individuals with hypertension (diabetic: 55; non-diabetic: 84). When stricter goals were considered, the participants with diabetes exhibited poorer BP control rates at all the time-points of assessment $(23.6 \%, 27.3 \%$, and $29.1 \%)$ compared to the non-diabetic patients $(57.1 \%, 67.9 \%$, and $69.0 \%)(\mathrm{p}<0.001)$. When the standard goals were applied to both groups $(<140 / 90)$, no differences in control rates between the groups were observed ( $p>0.05$ ). Specifically, the BP control rates in the group of patients with $\mathrm{DM}$ at the three time-points were $47.3 \%, 61.8 \%$, and $60.0 \%$. In the case of SPB, there was no difference in mean values (continuous variable) when compared between diabetic and non - diabetic hypertensives ( $p>0.05$ ), in all evaluations. And, in the case of DBP, the values have been reduced over time in both groups of patients.
\end{abstract}

Conclusion: The presence of DM was associated with poorer BP control rates when stricter goals were considered; this difference disappeared when similar goals were applied to both groups.

Keywords: Hypertension; Blood Pressure control; Type 2 diabetes mellitus.

Abbreviations: Millimeters of Mercury: mmHg; type 2 Diabetes Mellitus: 2DM; Blood Pressure: BP; Diastolic Blood Pressure: DBP; Systolic Blood Pressure: SBP; Body Mass Index: BMI; Confidence Interval: CI.

\section{Strengths And Limitations of This Study}

All patients have a long time of treatment in reference service for arterial hypertension.

Hypertensive patients who developed DM between 2004 and 2015 were also excluded to avoid exposure time bias. These patients were removed from this study so that we could keep the Closed Cohort design.

Due to the study design, the number of participants eligible to participate in the study was reduced.

This study analyzed only the number of antihypertensive that the participants used and did not take into account the classes of medications used. Another article is being done to make this association, considering the Brazilian guidelines for the treatment of hypertensive patients.

\section{Introduction}

Type 2 Diabetes Mellitus (DM) and hypertension often coexist, with the global prevalence of both having increased in recent years [1]. The presence of DM in combination with hypertension can be considered fatal given that it increases cardiovascular risks, leads to more rapid damage to the body, and consequently elevates morbidity and mortality. In turn, hypertension is likely the most relevant predictor of cardiovascular events in individuals with DM [2].

In patients with DM with hypertension, a reduction in Blood Pressure (BP) levels can reduce cardiovascular mortality independently from glycemic control due to a reduction of the incidence of cardiovascular events and target organ injury [3, 4]. It is estimated that two-thirds of individuals with DM do not attain BP below 130/80 mmHg [1].

Recent studies that investigated BP control in individuals with DM considered specific groups of patients with both conditions and performed cross-sectional analyses only, without the followup analysis needed to assess the progression of risk over time [2, 
$5,6]$. The innovative purpose of this study is to analyze a group of hypertensive patients with and without type 2 diabetes mellitus who were treated at a reference center for the control of arterial hypertension for a long time and not only a transverse cut in time, in order to allow a temporal evaluation of variation of blood pressure control among these populations.

The aim of the present study was to assess BP behavior by monitoring a historical cohort of patients with continuous hypertension over 11 years at a hypertension reference center.

\section{Methods}

The present study was a non-concurrent cohort study conducted with patients with hypertension and diabetes who were regularly followed for a minimum of 11 years. The analysis was performed in 2015 at a reference center for hypertension in the Center-West area of Brazil, and all participating patients signed an informed consent form. The consent was signed when the patients attended the clinic visit at the last evaluation followup (2015), and at the same time, the participants gave their data from the medical records for analysis of previous data.

The cohort included hypertensive individuals with and without diabetes who were regularly followed at the study setting, i.e., with visits every three months since 2004. Followup was performed according to the guidelines formulated by the Brazilian Society of Cardiology [7] to define the most adequate treatment for each individual patient.
Individuals with a diagnosis of chronic kidney disease at the cohort onset were excluded from the study and those in use of illicit psychoactive substances, as well as current use of antiinflammatory medications. Our patients are educated about the chronic use of anti-inflammatory drugs and their repercussions on health. Hypertensive patients who developed DM between 2004 and 2015 were also excluded to avoid exposure time bias. The service medical records were surveyed in 2015, which allowed the identification of (i) 71 individuals with hypertension and diabetes at the study onset in 2004; (ii) 84 individuals with hypertension who developed DM during the 11-year follow-up period; and (iii) 270 individuals with hypertension who did not have DM at baseline and who did not develop DM from 2004 to 2015. The individuals with hypertension and diabetes in 2004 were considered as the exposure group, and those without DM were randomly selected in adequate numbers to match the population of patients with hypertension and DM (Figure 1).

The cohort was followed for 11 years, and the participants were assessed at three time-points: baseline (2004), mid-term (2009), and the end of follow-up (2015). The first two assessments were based on data gathered from the participants' medical records. For the final assessment, individual appointments were scheduled. During these appointments, in addition to data collection, the participants were assessed for blood pressure, body weight, and stature and were requested to provide samples for biochemical tests.

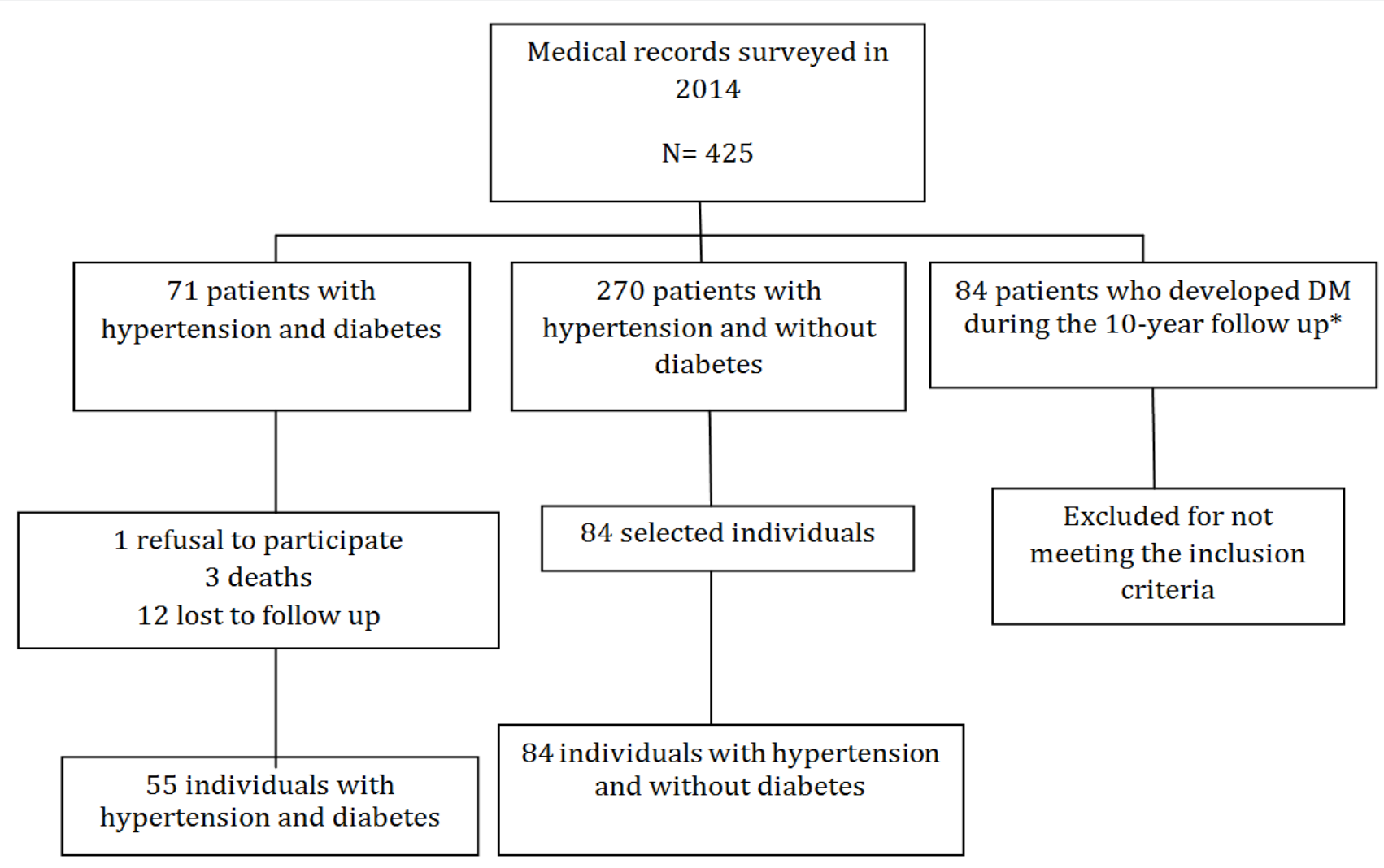

Figure 1: Flowchart representing inclusion in the cohort. Goiânia, Goiás state, Brazil, 2015.

* No case of chronic kidney disease (CKD) was identified at baseline

Citation: De Sousa AC, Magalhães FG, et al. (2017) Blood Pressure Control in an 11-Year Cohort of Diabetic and Non-Diabetic 
Sociodemographic and clinical variables were assessed, including time since diagnosis of hypertension, time since diagnosis of diabetes, the duration of treatment at specialized service, BP, glycated hemoglobin levels, lipid profile, Body Mass Index (BMI) and the use of antihypertensive medications, which were recorded according to the class of medication and prescription. The classes considered were: beta blockers, diuretics, Angiotensin Converting Enzyme Inhibitors (ACEI), Angiotensin II Blockers (ARBs), calcium channel blockers.

BP was assessed based on the values recorded in special forms routinely used at the service; the values recorded during the first visit in 2004 and 2009 were considered for the baseline and mid-term assessments, respectively, the latter being five years after the study onset.

At the final assessment, BP was measured using a semiautomatic OMRON HEM-705CP device and according to the technique described in the VI Brazilian Hypertension Guidelines (VI Diretriz Brasileira de Hipertensão) [7]. Three measurements were performed at one-minute intervals, and the average of the last two measurements was used for data analysis. BP control was defined according to the classification formulated in the Brazilian Hypertension Guidelines as $<130 / 80 \mathrm{mmHg}$ and $<140 / 90 \mathrm{mmHg}$ [7] for participants with and without DM, respectively.

\section{Statistical analysis}

Qualitative variables were described as absolute frequencies and proportions, and associations were analyzed using the chi-square or Fisher's exact test, as appropriate. Quantitative variables were described using the mean, standard deviation, median and Confidence Interval (CI). The means were compared only after the data distribution analysis using the KolmogorovSmirnov test and application of the parametric Student's t-test.

Logistic regression analysis was performed to investigate the relationship between predictive variables and the categorical outcome "blood pressure control". To construct the final models, a univariate analysis was first performed using partial models that were generated using the forward-conditional method. Predictive variables were selected in the partial models for inclusion in the final model, considering amplified significance values of $\mathrm{p} \leq 0.20$. The significance level was set to $5 \%$ and CI to $95 \%$ in all the tests.

\section{Results}

A total of 139 patients with hypertension participated in the study (55 with DM and 84 without DM). The average age was similar in both groups (57.5 years \pm 9.3 ). At baseline, the average time since diagnosis of hypertension was 16.5 years $( \pm 9.5)$ in the group with DM and 12.2 years $( \pm 7.32)$ in the group without DM $(\mathrm{p}<0.05)$. In addition, the duration of antihypertensive treatment at the specialized service was similar in both groups (5.9 years $( \pm 3.9)$ ). The average time since diagnosis of DM at baseline was 4.0 years $( \pm 6.0)$.

The groups were similar relative to the analyzed sociodemographic, clinical and lifestyle variables, except for BMI, as the frequency of excess weight was higher in the group with DM (Table 1).
BMI did not exhibit significant changes over time in any group. The values in the group of participants with DM were 31 $\mathrm{kg} / \mathrm{m} 2( \pm 5.6)$ and $30.5 \mathrm{~kg} / \mathrm{m} 2( \pm 6.0)$ at baseline and at the end of follow up. For the group without DM, these values were $26.7 \mathrm{~kg} /$ $\mathrm{m} 2( \pm 4.1)$ and $27.1 \mathrm{~kg} / \mathrm{m} 2( \pm 4.5)$, respectively. These intragroup differences were not statistically significant ( $\mathrm{t}$-student test).

The average Systolic Blood Pressure (SBP) was similar between the groups over time ( $p>0.05$ - Friedman variance test). In the group with DM, the lowest average value was 136.3 $\mathrm{mmHg}$ (measured at the mid-term assessment), and the highest value was $138.4 \mathrm{mmHg}$ (measured at the end of the study). At no time was the average SBP higher than $140 \mathrm{mmHg}$. In the group without DM, the lowest value was $131.2 \mathrm{mmHg}$ at the mid-term assessment; the average value at the other two assessments was $133.0 \mathrm{mmHg}$ (Graph 1).

The diastolic blood pressure (DBP) values exhibited significant reduction $(\mathrm{p}<0.05)$ from baseline to the last assessment in both groups. In the group with DM, the average DBP was $85.8 \mathrm{mmHg}$ $( \pm 14.7)$ at baseline and $74.8 \mathrm{mmHg}( \pm 11.1)$ at the end of the study, with an average absolute reduction of $11 \mathrm{mmHg}$. In the group without DM, the average DBP was $84.5 \mathrm{mmHg}( \pm 13.2)$ at baseline and $74.1 \mathrm{mmHg}( \pm 10.3)$ at the end of the study, with an average absolute reduction of $10.4 \mathrm{mmHg}$. The average DBP was similar between the groups at all time-points (Graph 1).

By the Friedman's analysis of variance, we also find that both groups showed no significant difference between the SBP in 3 segments (group with DM: 137.5 / 136.3 / 138.4mmHg, and group without DM: 133.8 / 131.2 / $133.1 \mathrm{mmHg}$ ). The averages of diastolic blood pressure had different behavior, with a significant reduction (group with $\mathrm{p}>0.05$ - U Mann-Whitney Test).

The group with DM exhibited poorer BP control rates compared to the group without DM when stricter goals were applied to the former (Table 2).

When the groups were compared using the same, less strict BP goals $(<140 / 90 \mathrm{mmHg})$, no difference in BP control rates was observed $(p>0.05)$ (Table 2). When this parameter was applied, the rate of $\mathrm{BP}$ control among the participants with DM was $47.3 \%$ in 2004 , increasing to $61.8 \%$ in 2009 and remaining at a similar level (60\%) in 2015.

When the analysis was performed using the conventional SBP control goals selected for the present study $(140 / 130 \mathrm{mmHg})$, the groups exhibited similar behavior: the control rate increased from over $45 \%$ to $70 \%$ from baseline to the end of the study, with no difference between the groups.

With respect to DBP control, the rates were higher in the group with DM at baseline and mid-term, being 63.6\% and $76.4 \%$, respectively $(\mathrm{p}<0.05)$. At the end of the study, the DBP control rates were similar, being $92.7 \%$ and $90.5 \%$ in the groups with and without DM, respectively ( $p>0.05)$.

Relative to the prescribed pharmacological treatment, $73.7 \%$ of the participants used up to two classes of antihypertensive drugs, without any significant difference between the groups. The number of prescribed medications increased beginning at 
Table 1: Composition of non-concurrent cohort according to sociodemographic, clinical and lifestyle characteristics. Goiânia-GO, Brazil, 2004.

\begin{tabular}{|c|c|c|c|c|c|c|c|}
\hline & \multicolumn{2}{|c|}{ Hypertension and diabetes $(n=55)$} & \multicolumn{2}{|c|}{$\begin{array}{l}\text { Hypertension without } \\
\text { diabetes }(n=84)\end{array}$} & \multirow{2}{*}{\multicolumn{2}{|c|}{$\begin{array}{l}\text { Total } \\
(n=139)\end{array}$}} & \multirow[t]{3}{*}{$\mathbf{p}^{*}$} \\
\hline & \multirow[b]{2}{*}{$\mathbf{n}$} & \multirow[b]{2}{*}{$\%$} & \multirow[b]{2}{*}{$\mathbf{n}$} & \multirow[b]{2}{*}{$\%$} & & & \\
\hline & & & & & $\mathbf{n}$ & $\%$ & \\
\hline \multicolumn{8}{|l|}{ Gender } \\
\hline Male & 11 & 20 & 23 & 27.4 & 34 & 24.5 & 0.420 \\
\hline Female & 44 & 80 & 61 & 72.6 & 105 & 75.5 & \\
\hline \multicolumn{8}{|l|}{ Race } \\
\hline White & 30 & 57.7 & 42 & 54.5 & 72 & 55.8 & \\
\hline Non-white & 22 & 42.3 & 35 & 45.5 & 57 & 44.2 & 0.857 \\
\hline Not reported & 3 & 5.5 & 7 & 8.3 & 10 & 7.2 & \\
\hline \multicolumn{8}{|l|}{ Age range } \\
\hline$<50$ years of age & 12 & 21.8 & 22 & 26.2 & 34 & 24.5 & 0.804 \\
\hline $50 \mid--60$ & 22 & 40 & 30 & 35.7 & 52 & 37.4 & \\
\hline $60 \mid--70$ & 17 & 30.9 & 23 & 27.4 & 40 & 28.8 & \\
\hline 70 & 4 & 7.3 & 9 & 10.7 & 13 & 9.4 & \\
\hline \multicolumn{8}{|l|}{ Physical activity } \\
\hline Regular & 30 & 55.6 & 47 & 56 & 77 & 55.8 & \\
\hline Irregular & 5 & 9.3 & 13 & 15.5 & 18 & 13 & 0.488 \\
\hline None & 19 & 35.2 & 24 & 28.6 & 43 & 31.2 & \\
\hline Not reported & 1 & 1.8 & 0 & 0 & 1 & 0.7 & \\
\hline \multicolumn{8}{|l|}{ Smoking } \\
\hline Yes & 1 & 1.8 & 5 & 6 & 7 & 4.5 & \\
\hline No, I quitted & 21 & 38.2 & 27 & 32.1 & 48 & 34.5 & 0.430 \\
\hline Never smoked & 33 & 60 & 52 & 61.9 & 85 & 61.2 & \\
\hline \multicolumn{8}{|l|}{ Alcohol intake } \\
\hline Yes & 1 & 1.8 & 7 & 8.3 & 8 & 5.8 & 0.107 \\
\hline No & 54 & 98.2 & 77 & 91.7 & 131 & 94.2 & \\
\hline \multicolumn{8}{|l|}{ Body mass index } \\
\hline Normal weight & 9 & 16.4 & 27 & 32.1 & 36 & 25.9 & \\
\hline Overweight & 21 & 38.2 & 41 & 48.8 & 62 & 44.6 & $<0.003$ \\
\hline Obesity & 25 & 45.5 & 16 & 19 & 41 & 29.5 & \\
\hline
\end{tabular}

${ }^{*}$ Chi-square test.

the mid-term assessment, but there was no significant difference between the groups in this respect. The number of medications also increased at the end of the study and was significantly higher in the group with DM compared to the non-diabetic participants. At the final assessment, $85.2 \%$ of the participants with DM used three or more antihypertensive drugs versus $45.2 \%$ of those patients without DM (p<0.001) (Table 3).

In the group with DM, BP control was not associated with any of the nvestigated variables. In the group without DM, an association was found between BP control and the following sociodemographic, clinical and lifestyle variables at baseline: the lack of BP control was more frequent among males (38.9\%) and patients with excess weight $(50.9 \%)(\mathrm{p}<0.05)$. In addition, the number of antihypertensive drugs used by the patients without DM was associated with BP control: monotherapy proved to be the least efficacious, as only $25.0 \%$ of users achieved adequate BP control. 


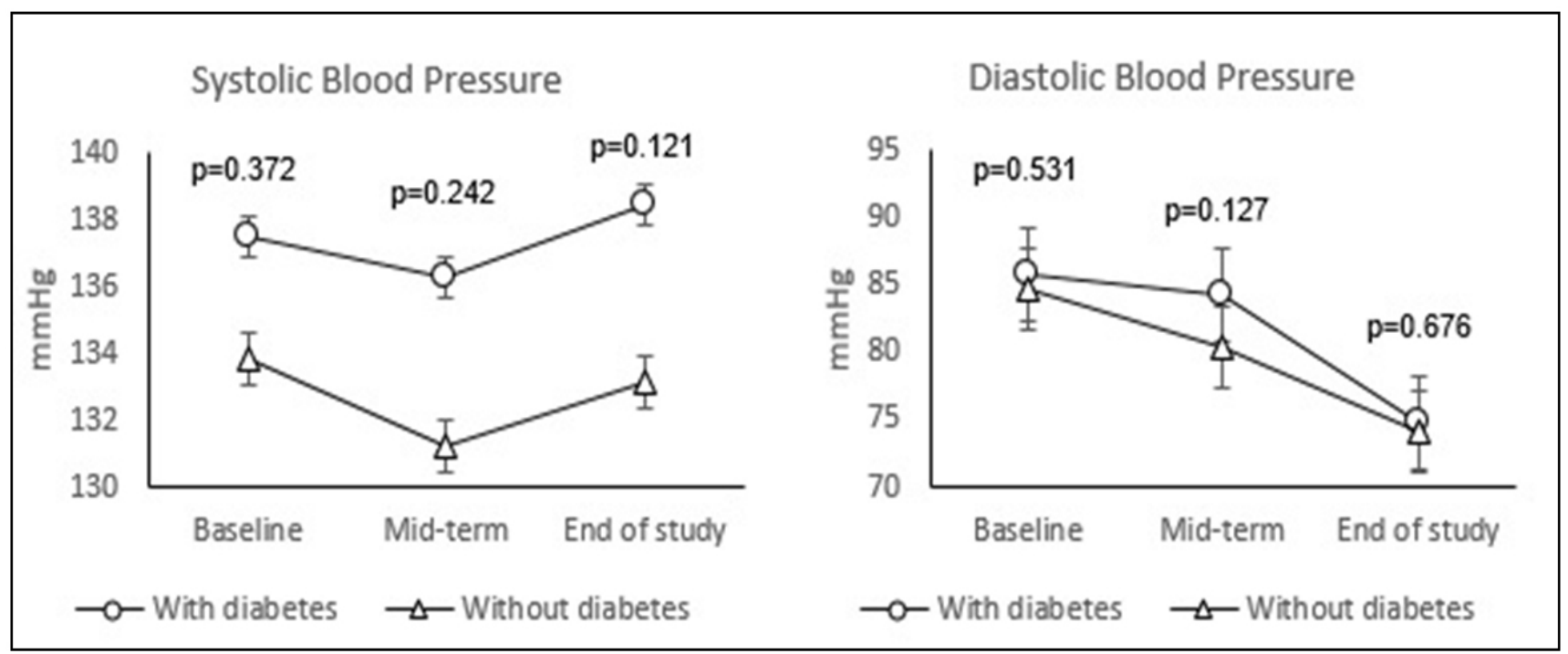

Graph 1: The distribution of average blood pressure among hypertensive individuals with or without diabetes over the 11-year follow up. Goiânia-GO, Brazil, 2015.

$\mathrm{p}={ }^{*} \mathrm{~T}$-Student Test

Table 2: Blood pressure control among hypertensive individuals with or without diabetes over the follow up period. Goiânia-GO, Brazil, 2015.

\begin{tabular}{|c|c|c|c|c|c|c|c|}
\hline \multirow{2}{*}{$\begin{array}{c}\text { Blood } \\
\text { pressure } \\
\text { control }\end{array}$} & \multicolumn{2}{|c|}{$\begin{array}{l}\text { Hypertension } \\
\text { and diabetes } \\
\qquad(n=55)\end{array}$} & \multicolumn{2}{|c|}{$\begin{array}{l}\text { Hypertension } \\
\text { without } \\
\text { diabetes } \\
(n=84)\end{array}$} & \multicolumn{2}{|c|}{$\begin{array}{c}\text { Total } \\
(n=139)\end{array}$} & \multirow[t]{2}{*}{$\mathbf{p}^{*}$} \\
\hline & $\mathbf{n}$ & $\%$ & $\mathbf{n}$ & $\%$ & $\mathbf{n}$ & $\%$ & \\
\hline \multicolumn{8}{|l|}{$\begin{array}{l}\text { Year } \\
2004\end{array}$} \\
\hline Yes** & 13 & 23.6 & 48 & 57.1 & 61 & 43.9 & $<0.001$ \\
\hline No & 42 & 76.4 & 36 & 42.9 & 78 & 56.1 & \\
\hline \multicolumn{8}{|l|}{$\begin{array}{l}\text { Year } \\
2009\end{array}$} \\
\hline Yes & 15 & 27.3 & 57 & 67.9 & 72 & 51.8 & $<0.001$ \\
\hline No & 49 & 72.7 & 27 & 32.1 & 67 & 48.2 & \\
\hline \multicolumn{8}{|l|}{$\begin{array}{l}\text { Year } \\
2015\end{array}$} \\
\hline Yes & 16 & 29.1 & 58 & 69 & 74 & 53.2 & $<0.001$ \\
\hline No & 39 & 70.9 & 26 & 31 & 65 & 46.8 & \\
\hline \multicolumn{8}{|c|}{$\begin{array}{l}\text { *Chi-square test. } \\
\text { **Blood pressure assessment parameters: Hypertension and diabetes }^{*}<130 / 80 \mathrm{mmHg} \text { and hypertension without diabetes }<140 / 90 \mathrm{mmHg} \text {. }\end{array}$} \\
\hline
\end{tabular}

Table 3: Pharmacological treatment of hypertensive individuals with or without diabetes in a historical cohort. Goiânia-GO, Brazil, 2015.

\begin{tabular}{|c|c|c|c|c|c|c|c|}
\hline \multirow[b]{2}{*}{$\begin{array}{l}\text { Pharmacological } \\
\text { treatment }\end{array}$} & \multicolumn{2}{|c|}{$\begin{array}{c}\text { Hypertension } \\
\text { and diabetes } \\
\quad(n=55)\end{array}$} & \multicolumn{2}{|c|}{$\begin{array}{l}\text { Hypertension } \\
\text { without } \\
\text { diabetes } \\
(\mathrm{n}=\mathbf{8 4})\end{array}$} & \multicolumn{2}{|c|}{$\begin{array}{l}\text { Total } \\
(n=139)\end{array}$} & \multirow{2}{*}{$\mathbf{p}^{*}$} \\
\hline & $\mathbf{n}$ & $\%$ & $\mathbf{n}$ & $\%$ & $\mathbf{n}$ & $\%$ & \\
\hline \multicolumn{8}{|l|}{ Year 2004} \\
\hline Monotherapy & 15 & 28.3 & 20 & 25 & 35 & 26.3 & \\
\hline 2 drugs & 24 & 45.3 & 39 & 48.8 & 63 & 47.4 & 0.899 \\
\hline$\geq 3$ drugs & 14 & 26.4 & 21 & 26.3 & 35 & 26.3 & \\
\hline \multicolumn{8}{|l|}{ Year 2009} \\
\hline Monotherapy & 7 & 12.7 & 11 & 13.1 & 18 & 12.9 & \\
\hline 2 drugs & 17 & 30.9 & 41 & 48.8 & 58 & 41.7 & 0.082 \\
\hline$\geq 3$ drugs & 31 & 56.4 & 32 & 38.1 & 63 & 45.3 & \\
\hline \multicolumn{8}{|l|}{ Year 2015} \\
\hline Monotherapy & 2 & 3.7 & 9 & 10.7 & 11 & 8 & \\
\hline 2 drugs & 6 & 11.1 & 37 & 44 & 43 & 31.2 & $<0.001$ \\
\hline$\geq 3$ drugs & 46 & 85.2 & 38 & 45.2 & 84 & 60.9 & \\
\hline
\end{tabular}


At the end of study, BP control was associated only with physical activity among the participants without DM: BP control was absent in $73.1 \%$ of the participants who did not practice any physical activity $(\mathrm{p}=0.004)$.

On multivariate logistic regression analysis, the presence of DM remained the single significant predictor of BP control. This exposure factor explained $21.9 \%$ of the lack of BP control in the group with DM (95\% CI 0.098 - 0.486; p<0.001).

The rate of glycemic control - defined as glycated hemoglobin levels up to $7 \%$ - increased over time among the participants with DM. The glycemic control rate was $16.4 \%$ at baseline and increased to $27.3 \%$ and $41.8 \%$ at mid-term and the end of the study, respectively $(\mathrm{p}<0.05)$. No relationship was found between glycemic control and BP control. Even though the glycemic control rate improved over time, $\mathrm{BP}$ control was not associated with time since diagnosis of DM.

The standardization of prescriptions between patients and this variable was not associated with blood pressure control; in the same way, the sociodemographic variables (age and sex). The time of diagnosis of hypertension and diabetes, and glycemic levels (glycated hemoglobin) were also not associated, even when analyzing variance [8].

\section{Discussion}

An analysis of blood pressure in a cohort of individuals with hypertension under regular follow-up for 11 years showed that the values were quite similar at the various time-points. In terms of the BP control goals based on Brazilian guidelines, the results indicated poor control rates among the participants with DM compared to those without DM at all of the assessed time-points. Considering BP $<130 / 80 \mathrm{mmHg}$ as a goal for patients with DM, the BP control rates vary considerably among different parts of the world. Higher control rates were found in South Korea, 66.3\% [9], followed by Canada, 53.6\% [8], the United States, 51.1\% [10], and South Africa, 45.8\% [11]. In contrast, the control rates in Italy and Ireland are below $25.0 \%$ [12] and are similar to those found in the present study. According to several studies conducted in different countries, patients with hypertension and DM achieve a better BP control when the goals are set to 130/80 $\mathrm{mmHg}$ than when these values are higher [13-15].

With respect to patients with hypertension and without DM, evidence indicates that BP control rates vary as a function of geographic location and how the values used for rate calculation are considered. In a recent study conducted in Portugal, which considered the identified prevalence rate instead of the patients who reported regular treatment for hypertension only, the rate of BP control was $42.5 \%$ [16]. In contrast, the rate found in a study conducted in Canada exclusively with patients under regular treatment was $64.6 \%$ [17]. In one study performed with employees at a higher education institution in the same city where the present study was performed, the BP control rate among the participants who reported to be under treatment was above $70 \%$ [18], which is close to the rate found in the present study.

It has been shown that the combination of diabetes and hypertension results in poorer BP control rates, and this effect is independent of geographic region and the type of healthcare system. The ideal BP values for individuals with diabetes are controversial; specifically, $<130 / 80 \mathrm{mmHg}$ and $<140 / 90 \mathrm{mmHg}$ are alternatingly adopted by different authors. The Brazilian Society of Cardiology defined values 130/80 mmHg as goals for patients with DM and stratifies the cardiovascular risk of patients with DM based on BP values [7].

The application of a stricter BP goal $(<130 / 80 \mathrm{mmHg})$ impacted the control rates exhibited by the population of our study. This phenomenon was also detected in other studies, showing that individuals with hypertension and DM have greater difficulties achieving more rigorous BP goals $[1,2,19]$.

SBP is more associated with vascular conditions and peripheral resistance, while DBP is more related to the state of the heart muscle and cardiac output components [20,21]. Vascular health is directly related to certain factors, among which age stands out [22]. Aging causes structural changes in arteries, which become stiffer, with consequent SBP elevation and DBP reduction. As a result, SBP tends to increase with age, while DBP increases until age 50 and then decreases [23]. These facts are noteworthy given that the population of the present study had an average age of 70 years at the end of the study.

There is still uncertainty and controversy regarding BP goals for patients treated for hypertension, especially those who are older than 60, a population in which SBP levels are usually higher [24]. Recently, the SPRINT study found that among patients with hypertension and high cardiovascular risk but without DM, a SBP treatment goal of $<120 \mathrm{mmHg}$ was associated with lower rates of cardiovascular events, including death, compared to a treatment goal $<140 \mathrm{mmHg}$ [25]. Therefore, the lower the value set as the BP control goal, the greater the obtained benefits, at least in a population of individuals with hypertension but without DM.

There is even more controversy in regard to the BP goals for patients with hypertension in combination with DM, and there is no consensus on this topic. The ACCORD study, in which individuals with hypertension and DM were subjected to intensive therapy for BP and glycemic control, found an isolated reduction of the stroke rate in the group treated to achieve the lowest goal (SBP $120 \mathrm{mmHg}$ ); however, there was an increase in the number of severe adverse events in the group subjected to this intensive therapy [26].

Following the publication of the SPRINT results in 2015, the authors of the ACCORD study recognized the limitations of their own study that were related to the intensive therapy for both BP and glycemia. These authors then announced their support for the idea that intensive reduction of SBP to $<120 \mathrm{mmHg}$ is beneficial for patients at high cardiovascular risk and that this goal ought also to be extended to individuals with hypertension and DM [27].

Several antihypertensive drugs and lifestyle changes are prescribed to achieve adequate BP goals. The drugs that are used to reduce BP must be used judiciously to avoid an excessive BP decrease [26]. Most patients require at least two antihypertensive drugs [28] to achieve adequate BP control. Patients with 
hypertension and DM require even more treatment, especially to achieve the recommended BP levels [29]. In our study, the number of antihypertensive drugs increased in both groups at all of the time-points; at the last time-point (2015), the group with DM used a larger number of medications compared to the non-diabetic participants. The prescriptions in the service where the study was carried out, follow the Brazilian guidelines for the treatment of arterial hypertension. These guideline recommend specific behaviors for each clinical situation, promoting individualized care [7].

While a larger number of drugs might be needed to treat hypertension in patients with $\mathrm{DM}$, in the end, this strategy might reduce the cost for both patient and healthcare system. This benefit may occur because the cost of antihypertensive treatment is lower compared to the costs of events triggered by the combination of hypertension and DM [30].

There is a paradox in the relationship between the potential of drugs to reduce BP and the number of agents that are actually prescribed. Specifically, the medications might result in very low BP levels, which can eventually lead to cardiovascular events. This phenomenon is known as the J-curve and tends to occur more particularly among older adults or individuals with established coronary artery disease [31, 32].

To summarize, when stricter BP goals are set for individuals with hypertension and DM, the rate of BP control is lower compared to non-patients with DM, even when using a larger number of antihypertensive drugs and when following the patients using a systematic protocol for the same length of time at a specialized service. The poorer rate of BP control among the participants with hypertension and DM when stricter goals were applied was primarily associated with the control of SBP.

\section{Conclusion}

In the present study, BP control was not associated with any of the investigated variables, except for the exposure factor, i.e., type 2 DM. This finding became evident upon considering different BP goals for the diabetic participants. While the BP control parameters for individuals with hypertension and DM are still controversial, the application of stricter goals to the group of participants with both conditions was associated with poorer BP control rates, demonstrating the difficulties these patients experience in meeting stricter goals.

Our results also show that, more than the values considered for blood pressure control among diabetic or non-diabetic hypertensive patients, we should look at the individual clinical situation of each patient and that, when the control criteria are matched, there is no difference in the behavior of the patient's blood pressure.

Therefore, efforts at achieving BP control should be more effective when stricter goals are applied so that the goals can be achieved and adverse effects to health can be minimized.

\section{Acknowledgment}

We thank the entire team of the Arterial Hypertension League HC/UFG.

\section{Ethics approval and consent to participate}

All of the participants were voluntary recruits who freely agreed to participate in the study. All participating patients signed a free and informed consent form. The study was conformed to the Declaration of Helsinki and approved by the Research Ethics Committee of the Clinical Hospital of the Federal University of Goiás (ruling no. 931,503).

\section{Authors' contributions}

All authors researched data, reviewed, edited the manuscript and contributed to discussion. All authors read and approved the final manuscript.

\section{References}

1. Campbell NR, Gilbert RE, Leiter LA, Larochelle P, Tobe S, Chockalingam A, et al. Hypertension in people with type 2 diabetes: update on pharmacologic management. Canadian family physician Medecin de famille canadien. 2011;57(9):997-1002.

2. Barquilla Garcia A, Llisterri Caro JL, Prieto Diaz MA, Alonso Moreno FJ, Garcia Matarin L, Galgo Nafria A, et al. [Blood pressure control in a population of hypertensive diabetic patients treated in primary care: PRESCAP-Diabetes Study 2010]. Semergen / Sociedad Espanola de Medicina Rural y Generalista. 2015;41(1):13-23. doi: 10.1016/j. semerg.2014.02.003

3. Patel A, Group AC, MacMahon S, Chalmers J, Neal B, Woodward M, et al. Effects of a fixed combination of perindopril and indapamide on macrovascular and microvascular outcomes in patients with type 2 diabetes mellitus (the ADVANCE trial): a randomised controlled trial. Lancet. 2007;370(9590):829-840.

4. Chen G, McAlister FA, Walker RL, Hemmelgarn BR, Campbell NR. Cardiovascular outcomes in framingham participants with diabetes: the importance of blood pressure. Hypertension. 2011;57(5):891897. doi: 10.1161/HYPERTENSIONAHA.110.162446

5. Boero R, Prodi E, Borsa S, Berti V, Fiorio E, Ferraro L, et al. Inadequate treatment and control of arterial hypertension in patients with type 2 diabetes mellitus. G Ital Nefrol. 2002;19(4):413-418.

6. Cheong AT, Tong SF, Sazlina SG, Azah AS, Salmiah MS. Blood pressure control among hypertensive patients with and without diabetes mellitus in six public primary care clinics in Malaysia. Asia Pac J Public Health. 2015;27(2):NP580-589. doi: 10.1177/1010539513480232

7. Brazilian Society of Cardiology, Brazilian Society of Hypertension, Brazilian Society of Nephrology. VI Brazilian guidelines on hypertension. Arq Bras Cardiol. 2010; 95: I-III.

8. Braga M, Casanova A, Teoh H, Gerstein H, Fitchett D, Honos G, et al. Poor achievement of guidelines-recommended targets in type 2 diabetes: findings from a contemporary prospective cohort study. Int J Clin Pract. 2012;66(5):457-464. doi: 10.1111/j.1742-1241.2012.02894.x

9. Lee YS. The current status of type 2 diabetes management at a university hospital. Korean Diabetes J. 2009;33(3):241-250.

10. Casagrande SS, Fradkin JE, Saydah SH, Rust KF, Cowie CC. The prevalence of meeting A1C, blood pressure, and LDL goals among people with diabetes, 1988-2010. Diabetes Care. 2013;36(8):22712279. doi: $10.2337 / \mathrm{dc} 12-2258$

11. Pinchevsky Y, Butkow N, Raal FJ, Chirwa T. The implementation of guidelines in a South African population with type 2 diabetes. Journal of Endocrinology. Metabolism and Diabetes of South Africa. 2013;18(3):154-158. 
12. Stone MA, Charpentier G, Doggen K, Kuss O, Lindblad U, Kellner C, et al. Quality of care of people with type 2 diabetes in eight European countries: findings from the Guideline Adherence to Enhance Care (GUIDANCE) study. Diabetes Care. 2013;36(9):2628-2638. doi: $10.2337 / \mathrm{dc} 12-1759$

13. Jung JH, Lee JH, Noh JW, Park JE, Kim HS, Yoo JW, et al. Current status of management in type 2 diabetes mellitus at general hospitals in South Korea. Diabetes \& metabolism journal. 2015;39(4):307-315. doi: $10.4093 / \mathrm{dmj} .2015 .39 .4 .307$

14.Webb EM, Rheeder P, Van Zyl DG. Diabetes care and complications in primary care in the Tshwane district of South Africa. Primary care diabetes. 2015;9(2):147-154. doi: 10.1016/j.pcd.2014.05.002

15. Morren JA, Baboolal N, Davis GK, McRae A. Assessment of treatment goals attained by patients according to guidelines for diabetes management in primary care centres in North Trinidad. Quality in primary care. 2010;18(5):335-343.

16. Polonia J, Martins L, Pinto F, Nazare J. Prevalence, awareness, treatment and control of hypertension and salt intake in Portugal: changes over a decade. The PHYSA study. Journal of hypertension. 2014;32(6):1211-1221. doi: 10.1097/HJH.0000000000000162

17. McAlister FA, Wilkins K, Joffres M, Leenen FH, Fodor G, Gee M, et al. Changes in the rates of awareness, treatment and control of hypertension in Canada over the past two decades. CMAJ : Canadian Medical Association journal. 2011;183(9):1007-1013. doi: 10.1503/ cmaj.101767

18. Jardim T, Neiva T, Rodrigues R, Arantes A, Barros C, Chinem B, et al. 5c.05: Differences in prevalence, awareness, treatment and control rates of hypertension between male and female. Journal of hypertension. 2015;33 Suppl 1:69e. doi: 10.1097/01. hjh.0000467535.06908.ec

19. Abellán Alemán J, Díaz MÁP, Hernández ML, Galindo SB, Iserte ADLS Claros NM, et al.Evaluation and control of hypertensive diabetic patients treated at primary care centers in Spain. Estudio BRAND II. Aten Primaria. 2011;43(6):297-304.

20. Banach M, Bromfield S, Howard G, Howard VJ, Zanchetti A, Aronow WS, et al. Association of systolic blood pressure levels with cardiovascular events and all-cause mortality among older adults taking antihypertensive medication. Int J Cardiol. 2014;176(1):219226. doi: 10.1016/j.ijcard.2014.07.067

21. Rock W, Leshno M, Shlomai G, Leibowitz A, Sharabi Y, Grossman E The association between ambulatory systolic blood pressure and cardiovascular events in a selected population with intensive control of cardiovascular risk factors. J Am Soc Hypertens. 2014;8(7):498502. doi: 10.1016/j.jash.2014.03.331

22. Jani B, Rajkumar C. Ageing and vascular ageing. Postgraduate medical journal. 2006;82(968):357-362. doi: 10.1136/pgmj.2005.036053

23. Williams B, Lindholm LH, Sever P. Systolic pressure is all that matters. Lancet. 2008;371(9631):2219-2221. doi: 10.1016/S01406736(08)60804-1

24.Stiefel P, García-Morillo JS, Villar J. Clinical Features, Cellular and Molecular Bases of Elderly Hypertension. Med Clin (Barc). 2008;131(10):387-395. DOI: 101016 / S0025-7753 (08) 72289-9

25. Group TSR. A randomized trial of intensive versus standard bloodpressure control. N Engl J Med. 2015;373(22):2103-2116.DOI: 10.1056/NEJMoa1511939

26. Cushman WC, Evans GW, Byington RP, Goff DC Jr, Grimm RH Jr, Cutler $\mathrm{JA}$, et al. Effects of intensive blood-pressure control in type 2 diabetes mellitus. N Engl J Med. 2010;362(17):1575-1585. doi: 10.1056/ NEJMoa1001286

27. Cushman WC, Evans GW, Cutler JA. Long-term cardiovascular effects of 4.9 years of intensive blood pressure control in type 2 diabetes mellitus: the action to control cardiovascular risk in diabetes followon blood-pressure study. Am Heart Assoc. 2015.

28. Lewington S, Clarke R, Qizilbash N, Peto R, Collins R. Age-specific relevance of usual blood pressure to vascular mortality: a metaanalysis of individual data for one million adults in 61 prospective studies. Lancet. 2002;360(9349):1903-1913.

29. Nilsson PM, Cifkova R, Kjeldsen SE. Treatment of hypertension in patients with type 2 diabetes mellitus. European Society of Hypertension. 2010;11(1):1-2.

30.Wiklund I, Halling K, Rydén-Bergsten T, Fletcher A. Does lowering the blood pressure improve the mood? Quality-of-life results from the Hypertension Optimal Treatment (HOT) study. Blood Press. 1997;6(6):357-364.

31. Bangalore S, Kumar S, Lobach I, Messerli FH. Blood pressure targets in subjects with type 2 diabetes mellitus/impaired fasting glucose: observations from traditional and bayesian random-effects metaanalyses of randomized trials. Circulation. 2011;123(24):2799-2810. 9 p following 810. doi: 10.1161/CIRCULATIONAHA.110.016337

32. Dorresteijn JAN, van der Graaf Y, Spiering W, Grobbee DE, Bots ML, Visseren FLJ. Relation between blood pressure and vascular events and mortality in patients with manifest vascular disease: J-curve revisited. Hypertension. 2012;59(1):14-21. doi: 10.1161/HYPERTENSIONAHA 